\title{
Evaluation of second year MBBS students perceptions and experiences towards tutorials as a teaching-learning method in pharmacology
}

\author{
Ravindra S. Beedimani*, Sameer Uz Zaman, Rameez Ahmed, Madhu Dhakshayani K, \\ L. Ramesh, K. Santosh Kumar
}

Department of Pharmacology, Kamineni Academy of Medical Sciences and Research Centre (KAMSRC), Hyderabad, Telangana, India

Received: 14 April 2016 Accepted: 07 May 2016

*Correspondence to: Dr. Ravindra S. Beedimani, Email: ravisb123@gmail.com

Copyright: (C) the author(s), publisher and licensee Medip Academy. This is an openaccess article distributed under the terms of the Creative Commons Attribution NonCommercial License, which permits unrestricted noncommercial use, distribution, and reproduction in any medium, provided the original work is properly cited.

\begin{abstract}
Background: The purpose of teaching is to facilitate effective learning. The commonly used instructional methods in pharmacology include lectures, case studies or clinical pharmacology problems, practicals, and tutorials. The aim of this study was to determine the perceptions and experiences of second-year MBBS students towards tutorials in pharmacology.

Methods: This cross-sectional study was carried out by the department of pharmacology at Kamineni Academy of Medical Sciences and Research Centre (KAMSRC), Hyderabad, Telangana, India. A total of 120 second-year MBBS students were interviewed with a structured questionnaire on tutorials. Responses to questions were expressed as percentage (\%) of the total number of participants.

Results: $88 \%$ of the learners admitted that it was necessary to have tutorials and only $57 \%$ accepted for it to be made mandatory. On being questioned to mention reasons for not attending tutorials, $58 \%$ stated that they were not prepared and lazy and 22\% learners were afraid of individual questioning. $80 \%$ suggested that the teacher and students should mutually decide the topic for tutorials. When asked about the environment during the tutorials, $48 \%$ students pointed out that only a few students dominated the tutorials. However, $34 \%$ considered that the atmosphere was friendly. On being enquired upon how the tutorial was conducted, $83 \%$ noticed that both the teacher and students participated during the tutorial session.

Conclusions: The suggestions based on feedback from learners, should be kept in mind while conducting tutorials to make it fruitful experience for MBBS students.
\end{abstract}

Keywords: Tutorials, Small-group teaching methods, Pharmacology, MBBS students

\section{INTRODUCTION}

Current teaching of pharmacology in the medical curriculum especially in India is primarily drug-centered and imparts factual knowledge instead of therapeutic skills. ${ }^{1}$ As opposed to traditional and passive didactic lectures, active-learning strategies address the educational content in an interactive learning environment to develop interpersonal, communication, and problem-solving skills needed by future doctors to function effectively in their new roles. ${ }^{2}$ The educational focus has shifted from basic sciences to clinical sciences and integrated courses to provide medical graduates with higher levels of competence and specialized skills. ${ }^{3,4}$ Various alternative teaching-learning methods are being used in many medical colleges to reinforce didactic lectures. Smallgroup teaching can take on a variety of different tasks such as problem-solving, role-playing, brainstorming, and debate. Tutorials are an important teaching-learning tool for smaller groups. ${ }^{5}$ Tutorials are an interactive problemsolving session to a smaller-group of 10-30 students. The Medical Council of India has emphasized the need to include tutorials in its latest reforms in medical curricula. Considering this diversity in teaching, we thought of eliciting the opinion of second-year MBBS students to consider their views on tutorials. The aim of the present study was to find out the perceptions and experiences of second year MBBS students towards tutorials in pharmacology. 


\section{METHODS}

After an Institutional Review Board approval (IRB), a total of 120 second-year MBBS students of the Kamineni Academy of Medical Sciences and Research Centre (KAMSRC), L.B Nagar, Hyderabad, Telangana, India who were due to appear $2^{\text {nd }}$ professional MBBS degree examinations in February, 2016 were interviewed with a structured questionnaire regarding their viewpoint on tutorials. The questionnaire was adapted from previous studies that assessed feedback of second-year medical students on tutorials in pharmacology. ${ }^{6}$ A few modifications were done to the questionnaire to best fit our style and format of tutorials in pharmacology. The questionnaire contained a total of 12 questions pertaining to students' perceptions and experiences towards tutorials in pharmacology. Some of the questions were closeended but the ones related to suggestions and comments on tutorials in pharmacology were open-ended. The questionnaire validation was done by a pilot study on 10 students. Each question had 3 to 7 options and they were asked to mark the single best option. The questionnaire is provided in the Appendix 1. Students were instructed not to reveal their identity in the questionnaire. Approximately twenty minutes was the time allotted for answering the questionnaire. At the end of each questionnaire, space was provided to students for their comments, suggestions and remarks. Questionnaires with more than three unanswered questions or multiple options marked were regarded as invalid and discarded. Tutorials for second year MBBS students were conducted once a week, for one-hour in the department of pharmacology at KAMSRC, Hyderabad, India. Each teaching faculty gets a batch of 12-15 students with whom the topics chosen primarily by the teachers was discussed during the tutorial. Students are notified about the topics of the tutorial at least two-weeks prior so that they have sufficient time to prepare.

\section{RESULTS}

Responses to questions were expressed as percentage (\%) of the total number of participants. Descriptive statistics was used for analysis of data and the results were expressed as a percentage (Table 1).

Table 1: Students response to tutorials questionnaire (\%).

\begin{tabular}{|c|c|c|c|}
\hline Questionnaire & \multicolumn{3}{|c|}{ Students response } \\
\hline $\begin{array}{l}\text { 1. Do you think it is necessary to } \\
\text { have tutorials in pharmacology? }\end{array}$ & Yes $(88 \%)$ & \multicolumn{2}{|l|}{ No $(12 \%)$} \\
\hline $\begin{array}{l}\text { 2. Should it be made compulsory to } \\
\text { attend tutorials? }\end{array}$ & Yes $(57 \%)$ & \multicolumn{2}{|l|}{ No $(43 \%)$} \\
\hline \multirow{2}{*}{$\begin{array}{l}\text { 3. State any } 2 \text { important reasons for } \\
\text { not attending tutorials. }\end{array}$} & Not prepared and lazy (58\%) & \multicolumn{2}{|c|}{ Afraid of individual viva (22\%) Not interested (11\%) } \\
\hline & Very frequent $(5 \%)$ & Teacher strict (3\%) $\quad \mathrm{M}$ & Monotonous/boring (1\%) \\
\hline $\begin{array}{l}\text { 4. What is your opinion about the } \\
\text { topics covered in the tutorials? }\end{array}$ & A very few important $(70 \%)$ & \multicolumn{2}{|c|}{ Repetition of the lectures (30\%) Not important (0\%) } \\
\hline $\begin{array}{l}\text { 5. Do you think students and teachers } \\
\text { should mutually decide the topic? }\end{array}$ & Yes $(80 \%)$ & \multicolumn{2}{|l|}{ No $(20 \%)$} \\
\hline $\begin{array}{l}\text { 6a. Is it important for students to read } \\
\text { the topic before the tutorial? }\end{array}$ & Yes $(96 \%)$ & \multicolumn{2}{|l|}{ No $(4 \%)$} \\
\hline \multirow{2}{*}{$\begin{array}{l}\text { 6b. If yes, why do students fail to } \\
\text { prepare for tutorial? }\end{array}$} & Heavy syllabus (32\%) & Lack of time (21\%) & Not easy $(9 \%)$ \\
\hline & \multicolumn{3}{|l|}{ Too many subjects $(5 \%)$. } \\
\hline $\begin{array}{l}\text { 7. If students fail to prepare for the } \\
\text { tutorial, do you think the purpose } \\
\text { of the tutorial is served? }\end{array}$ & Yes $(32 \%)$ & \multicolumn{2}{|l|}{ No $(68 \%)$} \\
\hline $\begin{array}{l}\text { 8. How is the environment during } \\
\text { tutorials? }\end{array}$ & Friendly $(34 \%)$ & The teacher is strict (18\%) & $\begin{array}{l}\text { A few students dominate } \\
(48 \%)\end{array}$ \\
\hline 9. How is the tutorial conducted? & Only the teacher talks (15\%) & $\begin{array}{l}\text { Only the students talk } \\
(2 \%)\end{array}$ & $\begin{array}{l}\text { Both the teacher and } \\
\text { students talk }(83 \%)\end{array}$ \\
\hline $\begin{array}{l}\text { 10. What should be the frequency of } \\
\text { tutorials? }\end{array}$ & Once in a week $(60 \%)$ & Once in two week $(30 \%)$ & Any other $(10 \%)$ \\
\hline $\begin{array}{l}\text { 11. What should be the duration of one } \\
\text { tutorial? }\end{array}$ & One-hour (71\%) & $<$ One-hour $(19 \%)$ & Two-hour $(0 \%)$ \\
\hline \multirow{3}{*}{$\begin{array}{l}\text { 12. Which of the following teaching- } \\
\text { learning method was most interesting? }\end{array}$} & Didactic lectures (25\%) & $\begin{array}{l}\text { Clinical pharmacology } \\
\text { problems }(16 \%)\end{array}$ & $\begin{array}{l}\text { Prescription writing } \\
(10 \%)\end{array}$ \\
\hline & Animal simulator practical $(6 \%)$ & Tutorials $(16 \%)$ & Students' seminars $(8 \%)$ \\
\hline & \multicolumn{3}{|c|}{ Multiple choice questions (MCQs) (19\%) } \\
\hline
\end{tabular}


Out of the 120 students who were interviewed with questionnaires, 100 completed questionnaires were accepted giving a response rate of $83.33 \%$. Regarding the topics covered in tutorials, $30 \%$ students felt that the tutorial topics were a repetition of lectures and $70 \%$ reported that very few important topics were covered in tutorials. $80 \%$ students suggested that the teacher and the students should mutually decide the topics of the tutorial. When enquired about the environment during the tutorial session, $48 \%$ indicated that only a few students dominated the tutorial and $18 \%$ considered the teachers as strict. However, $34 \%$ stated that the atmosphere was friendly during tutorial session (Figure 1). When probed about the way the tutorials were conducted, $83 \%$ pointed out that both the teacher and students participated actively in the class. However, $15 \%$ contemplated that only the teacher talks during the tutorial session (Figure 2). Regarding the comments, suggestions and remarks, a large number of students recommended incorporating multiple choice questions (MCQs) and case studies in the tutorials.

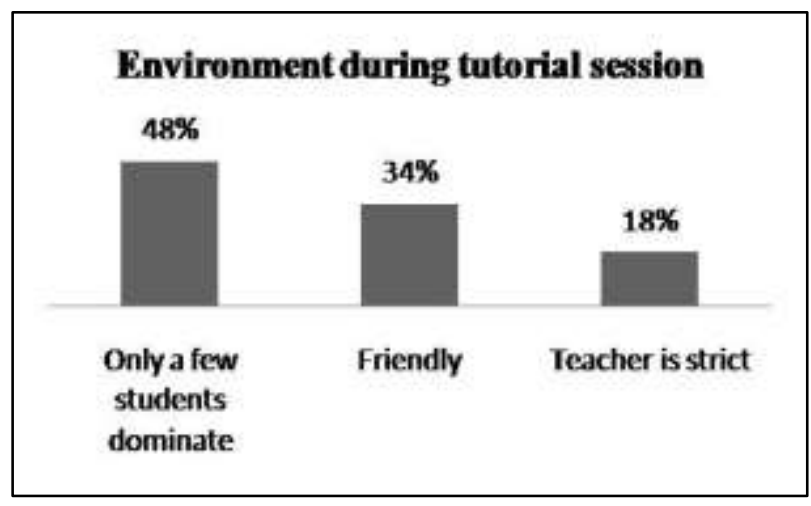

Figure 1: The environment during tutorial session.

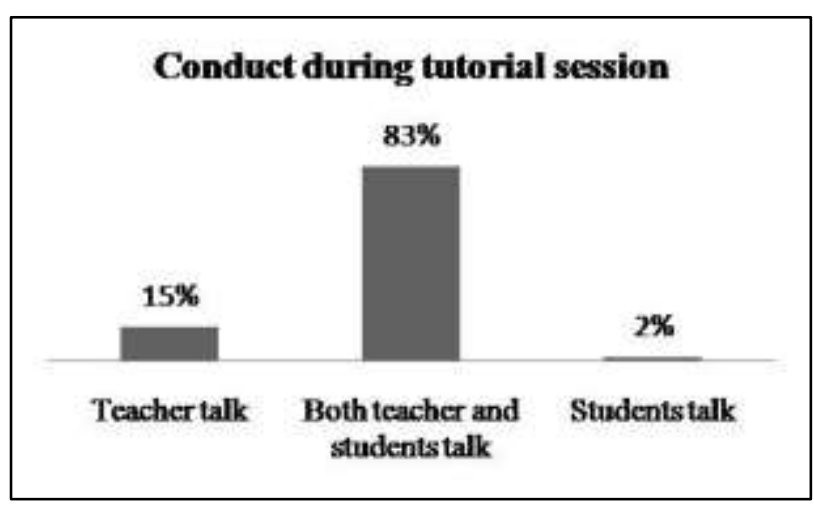

Figure 2: The conduct during tutorial session.

\section{DISCUSSION}

Traditional didactic lecture is a common method for teaching, but it may not stimulate higher-order thinking and students may also be hesitant to express and interact during the lecture. The teaching-learning methods need to be more structured and focused on therapeutics rather than feeding students with theoretical knowledge. ${ }^{7}$

Many studies have shown that the small-group teaching method is better for understanding different aspects of therapeutics like analysing the clinical case scenario and applying clinical pharmacology knowledge in writing prescriptions. $^{8,9}$

Students also endorsed that the small- group teachinglearning method is better for interaction among themselves and also with the teachers. ${ }^{10}$ In view of the principles of adult learning, where motivation and interaction are important, teaching-learning therapeutics in small-groups deserves a serious consideration in medical curricula.

Although an overwhelming $88 \%$ students agreed that it was necessary to have tutorials, on an average only $60 \%$ of students attended tutorials. It was interesting to note that only $57 \%$ students recommended that the tutorials should be mandatory. However, $43 \%$ did not like the idea of obligation for tutorials. This study tried to find out the reasons for such a poor response to tutorials. We explored that students did not attend tutorials regularly for various reasons. The list of reasons for not attending tutorials was as follows:

- $\quad$ Not prepared and lazy $(58 \%)$

- Afraid of individual questioning (22\%)

- $\quad$ Not interested $(11 \%)$

- Very frequent (5\%)

- $\quad$ Strict teacher $(3 \%)$

- Monotonous and boring (1\%)

Therefore, it can be construed that poor attendance for tutorials could be due to students trying to avoid embarrassment during individual questioning and hide their failure of preparation. It is one of the primary responsibilities of the educators to create a friendly environment and reassure that the students' feel comfortable especially during tutorials. $11 \%$ students commented that they were not interested in tutorials and in this regard the teaching faculty should bring forth innovative ideas to create students interest in the tutorial by incorporating relevant podcasts, movies, stories, roleplaying and game-based learning in the tutorials.

Another reason for low student interest could be due to inconsistency in adherence to tutorial schedule where students have to prepare for the topic repeatedly and may lose interest. Therefore, teachers should ensure that tutorials are conducted regularly as per schedule. Among the students who attended the tutorials, a significant proportion of students did so without adequate preparation in spite prior notice. As a result, there was hardly any useful discussion between the teachers and the students and the tutorial did not serve its purpose. 
The list of reasons stated by the learners for inadequate preparation includes;

- Heavy syllabus (32\%)

- $\quad$ Lack of time $(21 \%)$

- $\quad$ Not easy $(9 \%)$

- Too many subjects (5\%).

It is evident that medical students have to deal with information overload and also they have less time to prepare for tutorials after attending day-long college from 8 AM to 4 PM for 6 days a week. $95 \%$ students agreed that they should come prepared for the tutorials though they failed do so for various reasons. It can be contemplated that though they understand the importance of preparation for the tutorials but could not do it for various reasons. The primary objective of teaching pharmacology is to enable medical students to take rational therapeutic decisions in clinical practice. The overwhelming information imposed on the students hardly achieves these goals, mainly because the basic facts required for this purpose become subsumed in a sea of unnecessary information. The 200 drug list concept can be viewed as an effective way to reduce the "information overload" for students without sacrificing the quality of the course. Despite the limited number of drugs to study, the average score for the class on the pharmacology examination improved significantly after the introduction of this new concept. ${ }^{11}$

Regarding the topics of the tutorial, $70 \%$ students said that very few important topics were covered in tutorials and $30 \%$ said that the tutorials topics were just a repetition of the lectures. $80 \%$ of students suggested that teacher and students should mutually decide the topics. Although the tutorial topics are decided either by the university or respective department, mutual selection of the topics might generate more interest among students and also improve attendance and participation.

Regarding the environment during the tutorials, $46 \%$ revealed that only a few students dominated the tutorial sessions and $15 \%$ viewed the teachers as strict and rigid. During tutorial session, students who know too much or who are, by nature, dominating could hamper the learning process of other students. The educator needs to tactfully handle such a situation by ensuring that equal attention is paid to all the students. $83 \%$ students mentioned that both teacher and students participated actively during the tutorials, $15 \%$ students noted that only teacher talks during the tutorial session. We have to make sure that these important small-group teaching sessions are not conducted as didactic lectures. $71 \%$ of students expressed that one-hour duration for tutorial as optimal. $19 \%$ of students suggested shortening of duration to less than onehour and it should be appraised when planning the tutorials for the next semester.

Medical students recognize the unique and important role of peer-assisted teaching in medical education and its importance for their professional development. Peerassisted learning (PAL) has become increasingly popular over recent years with many medical colleges now formally incorporating peer-teaching programs into the curriculum. PAL has a sound evidence base with benefit to both peer-teacher and peer-learner. ${ }^{12,13}$ On being questioned about the most interesting teaching method, only $25 \%$ preferred didactic lectures, and the rest $75 \%$ collectively opted for small-group teaching methods like case studies, MCQs, tutorials, prescription writing, and animal simulator practicals. We can speculate that students really appreciate small-group and interactive teaching methods more than the traditional didactic lecture.

It can be concluded that the systematically organized tutorials can provide a framework within which the student can correlate the information gained from several sources.

\section{Funding: No funding sources}

Conflict of interest: None declared

Ethical approval: The study was approved by the Institutional Ethics Committee

\section{REFERENCES}

1. Achike FI. Teaching pharmacology in an innovative medical curriculum: challenges of integration, technology, and future training. J Clin Pharmacol. 2010;50(1):6-16.

2. Ghosh S. Combination of didactic lectures and caseoriented problem-solving tutorials toward better learning: perceptions of students from a conventional medical curriculum. Adv Physiol Educ. 2007;31(2):193-7.

3. Woodman OL, Dodds AE, Frauman AG, Mosepele M. Teaching pharmacology to medical students in an integrated problem-based learning curriculum: an Australian perspective. Acta Pharmacol Sin. 2004;25(9):1195-203.

4. Jaillon P. Teaching basic and clinical pharmacology to medical students: a 2006 survey in French schools of medicine. Therapie. 2006;61(5):439-46.

5. Tripathi RK, Sarkate PV, Jalgaonkar SV, Rege NN. Development of active learning modules in pharmacology for small group teaching. Educ Health. 2015;28(1):46-51.

6. Bhosale UA, Yegnanarayan R, Yadav GE. Attitude, perception and feedback of second year medical students on teaching-learning methodology and evaluation methods in pharmacology: A questionnaire-based study. Niger Med J. 2013;54(1):33-9.

7. Oshikoya KA. Teaching undergraduate MBBS pharmacology in Nigeria: a need for curriculum modification. West Afr J Med. 2007;26(3):256.

8. Wun YT, Tse EY, Lam TP, Lam CL. PBL curriculum improves medical students' participation 
in small-group tutorials. Med Teach. 2007;29(6):198-203.

9. Badyal DK, Bala S, Kathuria P. Student evaluation of teaching and assessment methods in pharmacology. Indian J Pharmacol. 2010;42(2):87-9.

10. Vora MB, Shah CJ. Case-based learning in pharmacology: Moving from teaching to learning. Int J Appl Basic Med Res. 2015;5(1):21-3.
11. Achike FI, Ogle CW. Information overload in the teaching of pharmacology. J Clin Pharmacol. 2000;40(2):177-83.

12. Goodfellow PB, Schofield E. Peer tutorials amongst medical students. Med Educ. 2001;35(10):1001-2.

13. Rees EL, Davies B, Eastwood M. Developing students' teaching through peer observation and feedback. Perspect Med Educ. 2015;4(5):268-71.

Cite this article as: Beedimani RS, Zaman SU, Ahmed R, Dhakshayani MK, Ramesh L, Kumar SK. Evaluation of second-year MBBS students perceptions and experiences towards tutorials as a teaching-learning method in pharmacology. Int J Basic Clin Pharmacol 2016;5:1112-7. 


\section{Appendix 1: Tutorials questionnaire.}

1. Do you think it is necessary to have tutorials in pharmacology?
a) Yes
b) No

2. Should it be made compulsory to attend tutorials?
a) Yes
b) No

3. State any 2 important reasons for not attending tutorials.

1 .

2. ............

3.

4. What is your opinion about the topics covered in the tutorials?
a) Not important
b) Repetition of the lecture
c) A few are important

5. Do you think students and teachers should mutually decide the topic?
a) Yes
b) No

6.A. Is it important for students to read the topic before the tutorial?
a) Yes
b) No

6.B. If yes, why do students fail to prepare for tutorial?

7. If students fail to prepare for the tutorial, do you think the purpose of the tutorial is served?
a) Yes
b) No

8. How is the environment during tutorials?

a) Friendly

b) The teacher is strict

c) A few students dominate

d) Any other

9. How is the tutorial conducted?
a) Only the teacher talks
b) Only the students talk
c) Both the teacher and students talk

10. What should be the frequency of tutorials?
a) Once in 2 weeks
b) Once a week
c) Any other

11. What should be the duration of one tutorial?

a) $<1 \mathrm{hr}$

b) $1 \mathrm{hr}$

c) $>1 \mathrm{hr}$

12. Which of the following teaching-learning method was most interesting?
a) Lectures
b) Clinical pharmacology problems
c) Prescription writing
d) Animal simulator practical
e) Tutorials
f) Students' seminars
g) Multiple choice questions (MCQs)

Any additional comments, suggestions and remarks 